\title{
Rewiring Museum Information: Mobile and Cloud
}

\author{
Atsushi Nobayashi
}

\begin{abstract}
At the National Museum of Ethnology, Japan (Minpaku), ImageFinder was designed to connect different kinds of information on an object through a new digital device: People search information not by using text but images of the objects instead. Another instrument called MAP (Minpaku Anthropological Phototheque) shows pictures taken by Minpaku staff in their fieldwork. These examples show that rapid progress in the design of digital devices and growth of the Internet community have changed the way to offer information on exhibitions and the museum itself. By connecting the information, visitors and users might find additional information or produce new contents and feed them back to the museum. As Minpaku collects materials concerned with human culture, we can show the existence of material culture in each period all over the world. Objects and information related to them would be our inheritance of intelligence on this planet.
\end{abstract}

\section{Introduction}

The aim of this paper is to introduce new methods of supplying information on the exhibits in the National Museum of Ethnology, Osaka, Japan (NME, Minpaku) and discuss their significance for the museum. These methods can show fundamental information on the objects displayed or stored in the museum and the results, new findings, and special knowledge of academic studies. Visitors to the museum can use them when they see the exhibits.

I will introduce two instruments: one is called ImageFinder and the other is called MAP (Minpaku Anthropological Phototheque). ImageFinder was developed as one of the media in the information zone in Minpaku. ImageFinder can contribute to making visitors to Minpaku aware of the existence of various kinds of information on the objects. MAP is used to supply different kinds of information on the exhibits from ImageFinder. We have a MAP for the regional cultures of China and it shows pictures that have been taken by Minpaku staff members. Not all of pictures

\footnotetext{
A. Nobayashi $(\bowtie)$

National Museum of Ethnology, Senri Expo Park, Suita, Osaka 565-8511, Japan

e-mail: nova@idc.minpaku.ac.jp 
are directly concerned with the objects in the exhibition, but they often provide background information relevant to exhibition themes.

I show how ImageFinder and MAP can supply information and then discuss the significance of supplying information in the museum. I especially focus on mobility and collectivity of information and discuss the possibility of these methods being used outside the museum.

\section{The Limit of Transmitting Information to Visitors in the Museum}

We can share various kinds of information in Minpaku and classify them as follows: (1) information on how to use the museum, (2) information on exhibits in the museum, and (3) information on the academic research of museum staff.

The information on admission fees, open days, and access map to the museum or plan of the exhibition hall are included in the first category. We have to provide them inside and outside the museum. The second information type is complicated. The name of the object, the area or country where it was collected, and the ethnic group or population that owned or used it belong to the second type of information in Minpaku. At the same time, the context in which it was used or the significance of the object in society also belong to the second type. They might, however, be treated differently when offered to visitors. The name, area, and ethnic group's name might be indicated in a caption to the objects in the exhibits. The object not only has fundamental information such as the name or original owner but also its cultural and historical background. They have been studied by academic staff and accumulated in the museum. There is a large volume of them and they cannot be explained only by the captions or panels that are usually set in the museum. They can be explained by other methods including electric devices or lectures by the museum staff. We can use different methods or ways to supply information on the objects to the museum visitors according to nature of the information (Nobayashi 2014a).

We also have to understand the nature of the media when we use them to supply information in the museum. We should recognize different media according to the contents of the information and the subjects to which we offer the information. For example, it is necessary to consider what words we should use in a pamphlet, the utilization of kanji (Chinese characters used in Japanese transcription), the size of the letters, the language according to the target age, nationality, and so on.

We cannot supply so much information in the exhibitions. The museum has limited space, available media, and number of staff who can support visitors. We have to select information to offer it effectively and efficiently to the visitors to the museum. Visitors might also see the museum exhibition within a limited time. If the museum tries to offer too much information on the exhibits, the visitors will be unable to digest most of it during their visit to the museum. 
When we understand that the information we can offer to the visitors is limited, we become aware of the strict conditions of offering information. Insufficient information about an object or exhibit might give visitors not only insufficient understanding but also wrong understanding. It is a major purpose of Minpaku to have visitors deepen their understanding of the history and the culture of human society with the exhibits. This cannot be achieved without enough information about human culture and society from the results of academic studies.

\section{Rewiring Various Information in the Museum: ImageFinder}

We were able to understand that we need to offer information at the museum to visitors for advancing their understanding. On the other hand, we know that information is distributed around the museum and some of it might not be in an easily accessible place. Some contents might be separated and visitors do not know that they are concerned with each other. Minpaku's exhibits are constructed with academic research and objects have been collected by the academic staff. They have also published books, articles, and essays as a result of their research and study. They have also accumulated at first hand materials including field notes, movies, pictures, and official documents while collecting materials. In fact, objects in Minpaku's exhibitions are rich in information concerning human culture and academic research. However, visitors do not necessarily have enough time to access them. The museum encourages its visitors to improve their knowledge or ideas by offering an appropriate means to provide information. It is most important for both visitors and the museum to have the chance and space to know the existence of various information relevant to the objects. We have to start sharing the information together.

We developed a new digital device offering information on the exhibits in Minpaku called ImageFinder under such conditions. It was designed to connect different kinds of information on an object through a digital device. The author engaged in developing it with the staff members of Minpaku, IT developers, and researchers. When we started the project, I showed a concept of the scheme to connect the existing contents in Minpaku (Fig. 1). We had used many kinds of media that offered information to the visitors to Minpaku but they were all independent.

We set the main purpose of the project as developing a means to show the connection of various information. We tried to make a new device that could wire the various information to the objects and show the connection and, as a result, have the users recognize the existence of information that is dispersed and not connected directly with the objects in the museum.

This system seems to work like a link collective site. It shows URL and users can move to the URL resource. What we tried to develop was different from such Internet linkage in the way of offering information. One reason is that we did not 


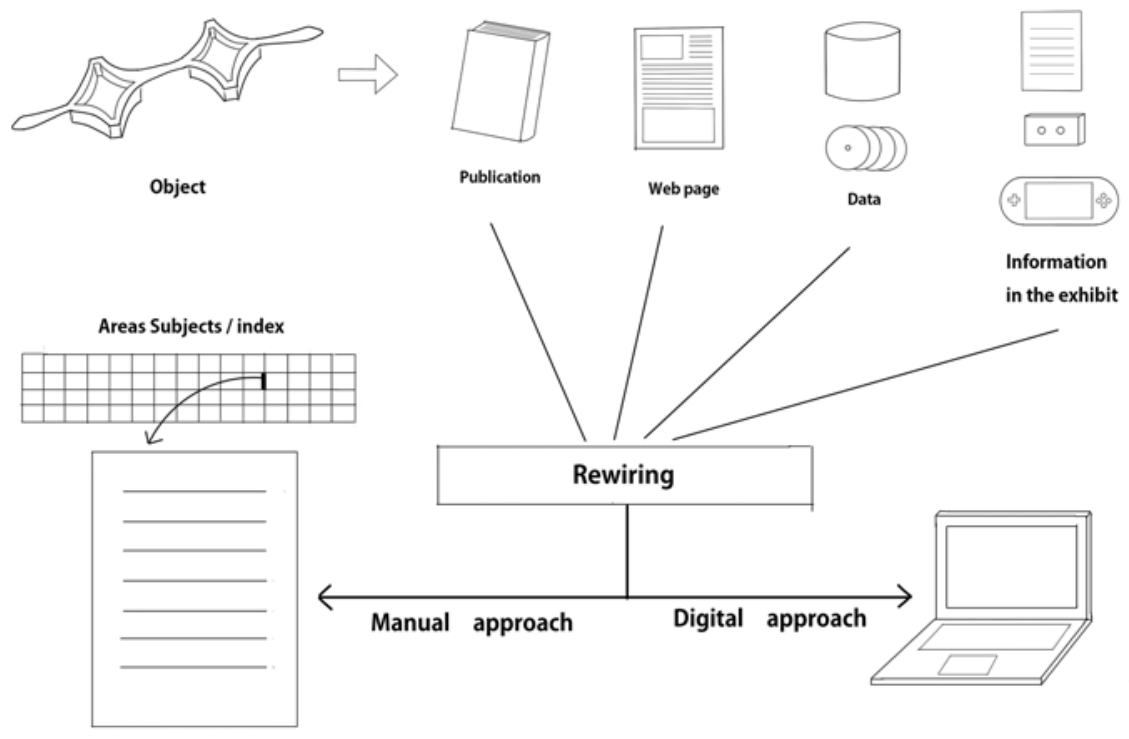

Fig. 1 A basic concept of the ImagFinder which the author offered at first

necessarily have all digital data of the information. It is sometimes difficult to make digital contents so that copyright is protected. We could not install all data in the same device. The other reason, what is more important, was that the new device was expected to encourage the visitors to search the information by themselves. To explore is the fundamental way of academic research. We expected the visitors to do autonomous activities (Fig. 2). We tackled the other important aspect in developing the device: a searching style without words. When we see an object for the first time and are interested in it, we try to collect information. We do not usually know the name, function, or its social context. We hoped that visitors would go through the same process as we did in our fieldwork. We therefore considered a way for people to search information not by using text but images of the objects instead. This might be an opposite direction for searching information in modern society where text searching is very popular for people using the Internet.

\section{The Possibility of Big Data: MAP (Minpaku Anthropological Phototheque)}

I also participated in another project to develop another digital device that could supply information on the exhibits. It was named Minpaku Anthropological Phototheque (MAP) and used in the exhibition "Regional Cultures of China" (Nobayashi 2014b). It showed pictures that were taken by Minpaku staff in their fieldwork. The picture itself is a useful medium in the museum. It shows the process 


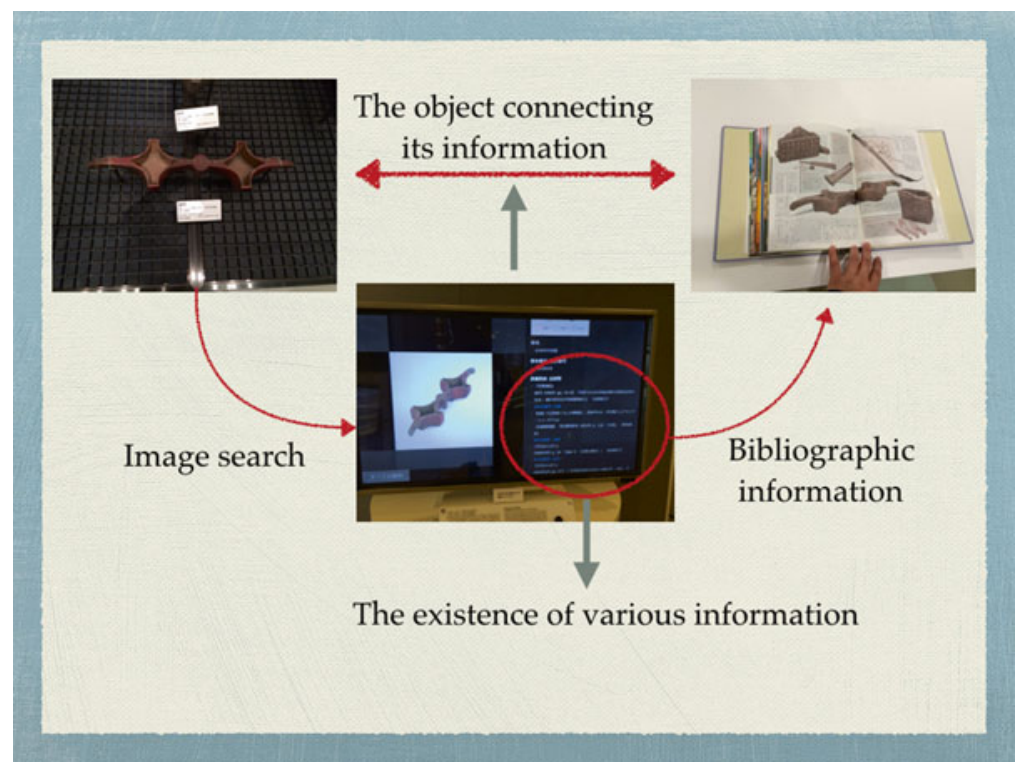

Fig. 2 Rewiring the object and its information by ImageFinder

of making or using objects concretely. It is used in museum exhibitions as a picture panel or printed in the catalogue. But there is limited space and we could not necessarily use pictures with the exhibits. In particular, the main purpose of the exhibition on "Regional Cultures of China" was to show variation in human cultures, and pictures were expected to be a useful medium for achieving it.

We planned a way of offering pictures to show the variations and changes of human culture as follows: to set pictures according to the location and time they were taken. We consulted with IT developers and designers to improve the operation system.

In MAP, pictures are distributed on a world map on a monitor screen according to the location they were taken. The users could select all of them according to the year they were taken (Fig. 3). The pictures were not necessarily concerned with the objects in the exhibition. But the users could understand the condition of the area that the exhibition was focusing on. They were also given plural "tags" concerned with the events and ethnic groups. Peoples could select and display pictures according to the time and the particular event. When a user selected a picture, a comment on it was displayed on the screen with a series of pictures that were taken at the same time.

The MAP system is currently working in the museum. However, it might be useful to use it outside the museum, especially on the Internet. In that case, it might be possible to supply and collect "big data" from the museum. 


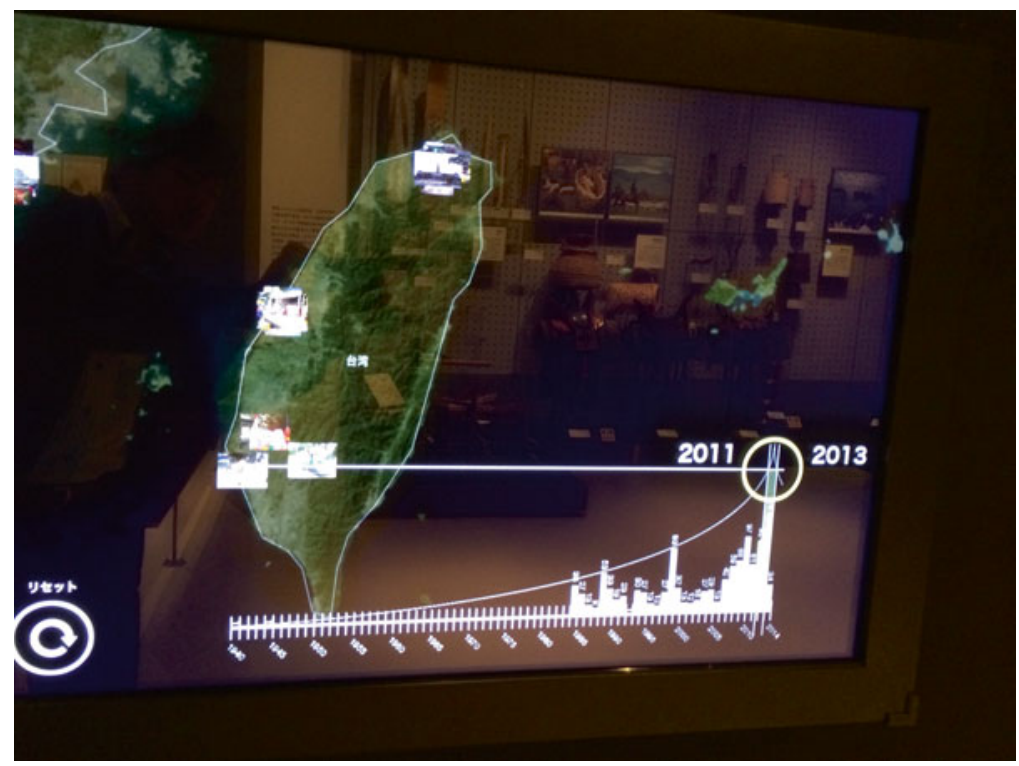

Fig. 3 Sorting pictures by years in MAP screen

We tend to think that an exhibition needs information concerned with the objects in the exhibition or the museum itself. The exhibits are a visible part of the museum and directly linked to the public. The museum has a chance to be evaluated with its exhibits. On the other hand, the exhibits change and the museum might collect additional information or new materials related to existing exhibits and materials or not. Individual exhibitions cannot continue to contribute to the museum and the public. We have to pay more attention to the materials stored in the museum. They also have rich contents or information as do the objects in current exhibitions. The museum could always open them to the public by other methods different from the exhibits. MAP could also be one of them.

A picture has rich information about people, animals, geography, weather, and artificial things including instruments, buildings, crafts, and so on. Even if a photograph has no image of people or artificial things and just shows the image of a cloud, it might be useful for meteorology with the data on the time and location. Digital cameras now record the time and location easily with a picture. It is much easier for us to order pictures according to the space and time than before.

They would also be historical records to those people who live in the area where the photographs were taken. It is more efficient and effective to open them to local society through SNS or other methods. The accumulated data would be passed down to the next generation and spread horizontally among the population with additional information. It is not necessary for the information in the museum to stay in the museum. 


\section{Conclusion}

The rapid progress of digital devices and the growth of the Internet community have changed the condition of museums, especially the way to offer information on exhibitions and the museum itself. Digital devices can handle various information that is separated from the object together because digital contents are easily duplicated. It lets the museum offer this information to the public in the museum and outside the museum at the same time. It is important to connect the information so that visitors can understand the exhibits efficiently and effectively. As a result, visitors and users might find additional information or produce new contents and feed them back to the museum. We are rewiring information from outside to the museum information. The museum and the users share the information that is not only in the museum but also in the hands of the users. This is mobility and cloud computing for information of the museum.

On the other hand, digital devices cannot autonomously offer information to visitors. We cannot imagine the museum without them, and digital devices and other digital media will become more important and develop further in future. We have partly achieved connection and integration of the museum's information by utilizing IT technologies. However, it depends on their utilization whether we can share the information with the museum visitors or users or not. We have to develop a way that stimulates visitors' intellectual curiosity and raises their literacy in dealing with museum information.

What do the objects and their information in the museum mean to us? In Minpaku, we have collected materials concerned with human culture. We have experienced rapid changes in our world during the twentieth and twenty-first centuries. We cannot see some of the material culture stored in Minpaku in their original places. We can show the existence of material culture in each period all over the world. People who are the original owners might use this information to create a new local material culture. The objects and their information in the museum will be our inheritance of intelligence on this planet.

Note ImageFinder and MAP system were developed by the cooperated work of the museum staff, designers of the exhibits and the developers of the computer system. It was also to rewire the knowledge and experience among the peoples.

Open Access This chapter is distributed under the terms of the Creative Commons AttributionNonCommercial 4.0 International License (http://creativecommons.org/licenses/by-nc/4.0/), which permits any noncommercial use, duplication, adaptation, distribution and reproduction in any medium or format, as long as you give appropriate credit to the original author(s) and the source, provide a link to the Creative Commons license and indicate if changes were made.

The images or other third party material in this chapter are included in the work's Creative Commons license, unless indicated otherwise in the credit line; if such material is not included in the work's Creative Commons license and the respective action is not permitted by statutory regulation, users will need to obtain permission from the license holder to duplicate, adapt or reproduce the material. 


\section{References}

Nobayashi, Atsushi. 2014a. A methodological study on tangible information on exhibits. In Museum stimulates sensibility - how to construct a visible, tangible, and sensual museum, ed. Y. Hirai et al., 65-96. Kyoto: Gakugei Publishing Co. Ltd.

Nobayashi, Atsushi. 2014b. You should consult the past if you want to create the future. Gekkan Minpaku 5: 6-7. (In Japanese). 